EISSN: $2706-7947$ ISSN: 2077- 4613

DOI: $10.36632 /$ mejas/2021.11.3.61

Journal homepage: www.curresweb.com

Pages: 813-822

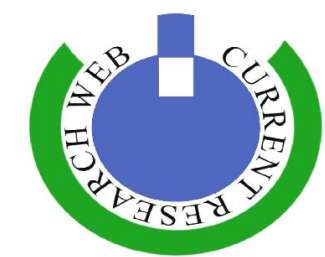

\title{
Effect of the Nozzle Shape and Diffuser on Droplet Size and its Precipitation Pattern for Gun Sprinkler
}

\section{Imam H. M.}

Department of Field Irrigation and Drainage Engineering Researches, Agricultural Engineering Research Institute, ARC, Egypt.

Received: 25 July $2021 \quad$ Accepted: 20 Sept. $2021 \quad$ Published: 30 Sept. 2021

\begin{abstract}
Gun sprinkler provides many distinguishes for on-farm water applicators but it produces a relatively high application rates and large droplets that tend to compact the soil surface and could damages leafs of seedlings. This work investigated the effect of orifice geometrical shape and adding diffuser vane on the droplet size and to improve the water precipitation pattern of the gun sprinkler. Three types of nozzles with an outlet orifice circular, square, and triangle shapes were standalone tested and with a diffuser vane of a $15^{\circ}$ diffusion angle. The use of non-circular shape nozzles reduced the gun sprinkler range of 2.33 to $9.76 \%$, but the use of diffuser vane reduced the range of 18.75 to $30.43 \%$. The noncircular shape nozzles improved the water precipitation pattern comparing the circular one. It produced a precipitation pattern with triangle shape and rectangle shape for square nozzle (SN) and triangle nozzle (TN) respectively. The circular nozzle $(\mathrm{CN})$ produced droplet diameter less than $5 \mathrm{~mm}$ under 4 bar operating pressure while both square (SN) and triangle (TN) nozzles had no significant effect on droplet diameter under different operating pressures. The use of diffuser vane reduced the droplet diameter near to $5 \mathrm{~mm}$ for Square nozzle with diffuser vane (SND) and Triangle nozzle with diffuser vane (TND) under 3 and 4 bar operating pressures respectively. The mean droplet diameter (arithmetic, and volumetric) decreased by increasing pressure, and Square nozzle with diffuser vane (SND) gave the best droplet sizes.
\end{abstract}

Keywords: gun sprinkler, droplet diameter, precipitation rate, nozzle shape.

\section{Introduction}

Recently, there is an expansion in using gun sprinkler especially in Egypt due to its lower energy requirements and operating and maintenance costs compared to center pivot irrigation systems. It's also facilitate the field mechanization processes because of the wider distances between the sprinkler risers compared with the ordinary sprinkler and drip irrigation systems. Gun sprinkler distinguished by a reduced operating labour, high water application uniformity with, good water management, and can be used on most crops, but they produce relatively high application rates and large water droplets that tend to compact the soil surface and to create run-off problems (Keller and Bliesner, 1990; Mostafa and Derbala, 2013). Large droplets could damages leafs of seedlings and cause fragmentation of the surface layer of the soil forming a crust layer which reduces soil infiltration rare (Ismail, 2009). When a dense fluid is ejected into a less dense fluid from a narrow slit whose thickness is much smaller than its width, a sheet of fluid can form. When the fluid is ejected not from a slit but from a hole, a jet forms. The fluid sheet and jet are inherently unstable and breakup easily (Lin, 2003). The drop size is determined by a competition between fluid inertia and surface tension, which allows for the prediction of the drop size from the Weber number and geometry of the nozzle (Kooij et al., 2018). Larger drop sizes are produced by increases in nozzle diameter, and by decreases in operating pressure (Solomon et al., 1985). Working pressure has the most influence on drop size; as pressure decreases drop size increases (Mentero et al., 2003). Sprinkler pressure and nozzle shape are major factors affecting droplet formation. For both circular and square nozzles, higher pressures created smaller droplet diameters over the entire droplet spectra. However, for a given pressure, changing nozzle shape from circular to non-circular also reduced

Corresponding Author: Imam H. M., Department of Field Irrigation and Drainage Engineering Researches, Agricultural Engineering Research Institute, ARC, Egypt. 
droplet diameters (Li, 1997; Abdel-mageed et al., 2009). Non-circular nozzles have the advantages of providing an acceptable water application pattern and a smaller portion of larger droplets over the entire precipitation profile at low pressure (Li et al., 1994).

The presented study targeted to reduce droplet size and to improve water precipitation pattern of gun sprinkler though both changing nozzle orifice geometrical shape and adding diffuser vane to sprinkler nozzle under low operating pressure conditions.

\section{Material and Methods}

Experiments were carried out at the National Irrigation Laboratory for On-farm Irrigation Devices Testing of Agricultural Engineering Research Institute (AEnRI), Dokki, Giza. Water application and droplet size distribution were tested indoors for HT-40G (penguin) water gun sprinkler,

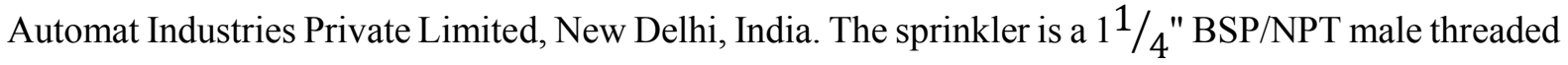
connection and $30^{\circ}$ trajectory angle fig. (1).

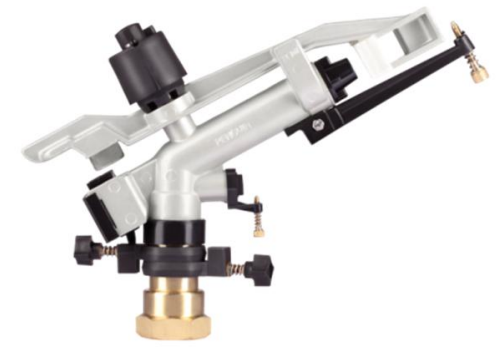

Fig. 1: HT-40G (penguin) water gun sprinkler.

Three types of teflon nozzles were fabricated with an outlet orifice circular, square, and triangle shapes. The fabricated nozzles design considered both orifice cross section area of $12 \mathrm{~mm}$ diameter, and slop inner angle $\left(8^{\circ}\right)$ of gun sprinkler original nozzle (Fig. 2). A special fittings were adapted to fit the fabricated nozzles with the sprinkler outlet thread consists of 1" UPVC nipple, and PE assembly nut (Fig. 3). A four vanes diffuser was made of $1 \mathrm{~mm}$ thickness aluminum sheet of a $15^{\circ}$ diffusion angle with flow direction through the nipple.

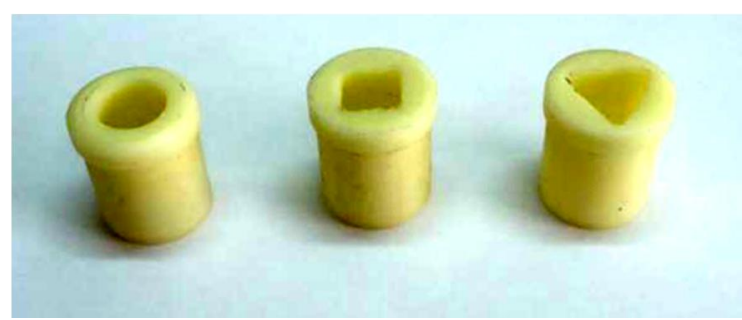

(1)

(2)

(3)

Fig. 2: Types of tiflon manufactured nozzles: 1. Circular, 2. Square, 3. Triangle.

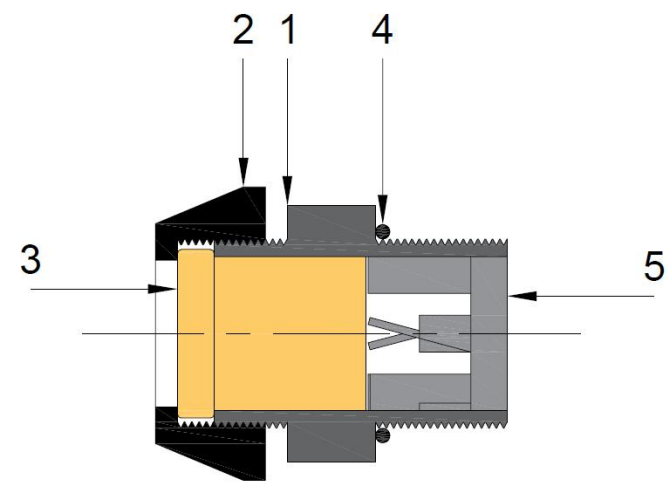

Fig. 3: Fitting Components of the manufactured nozzles: 1. 1" UPVC nipple, 2. PE assembly nut, 3. tiflon nozzle, 4. rubber seal ring, and 5. diffuser vane. 


\subsection{Gun sprinkler water distribution pattern}

The water distribution pattern of HT-40G gun sprinkler was tested (without using dispersion device) by arranging of catch cans radially from the sprinkler and ending at the end of the sprinkler spray stream with a $1.5 \mathrm{~m}$ spacing between each catch can (Fig. 4). The sprinkler was operated for 10 minutes with three replicates at 2, 3, and 4 bars operating pressure for every treatment without using the dispersion device. The volume of water in each catch cans was determined as the average of the three replicates. The experimental treatments were as shown in Table (1).

Table 1: The experimental treatments and its abbreviations.

\begin{tabular}{lc}
\hline Treatments & Abbreviations \\
\hline Circular nozzle without diffuser vane & (CN) \\
Square nozzle without diffuser vane & (SN) \\
Triangle nozzle without diffuser vane & (TN) \\
Circular nozzle with diffuser vane & (CND) \\
Square nozzle with diffuser vane & (SND) \\
Triangle nozzle with diffuser vane & (TND) \\
\hline
\end{tabular}

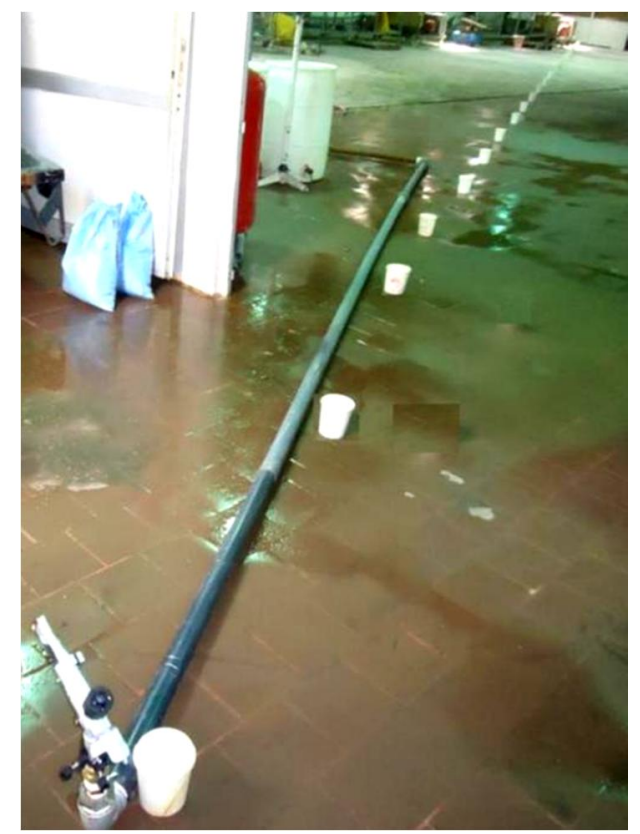

Fig. 4: Experimental set-up in the indoor laboratory.

\subsection{Droplet size test procedure}

A $90 \mathrm{~mm}$ wide by $19 \mathrm{~mm}$ deep glass petri dish with a cover was used to collect the water droplet samples from the water spray emitted from the gun sprinkler. The petri dish was half-filled with castor oil (Oleum ricini) (fig. 5). The cover was placed on the dish until it was opened at the desired location in the water spray. Droplets were allowed to collect in the oil for about one second, and then the cover was placed back on the petri dish. The dish was removed from the spray field, and the exterior was dried. The cover was removed, and the dish containing the oil and water droplets was imaged using Sony Cyber-shot DSC-W610 digital camera. The droplet size was determined using AutoCAD 2021 software. The captured image was imported to AutoCAD software, image scale adjusted, the perimeter of the droplets determined by circles, then the diameter of each circle was determined. A sample of as many as 40 droplets at least was measured from each specimen taken. The largest and smallest drops were cataloged for each petri dish specimen and listed in a spreadsheet. Water droplet samples were taken at 2, 3, and 4 bars operating pressure for the three types of nozzles. 


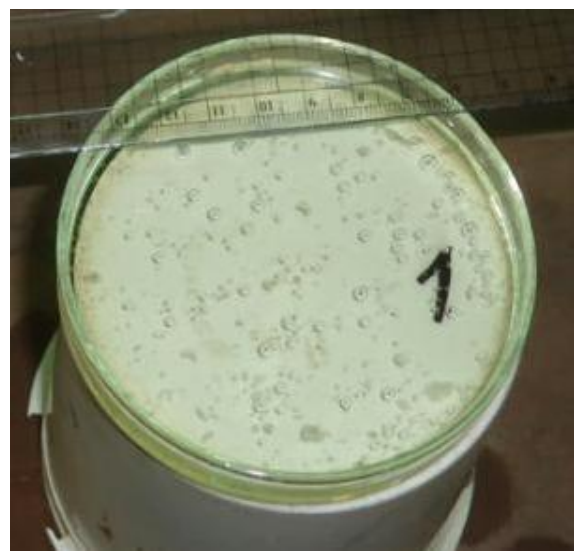

Fig. 5: A petri dish was half-filled with castor oil

\subsection{Basic drop statistics}

Different types of the tested nozzle produced a wide range of droplets size spectrum by air entrainment within the spray wetted area. Managing the large dataset obtained from captured images required a statistical approach. The parameters used in this work for drop diameter included arithmetic mean diameter (Equation (1)), volumetric mean $\left(\mathrm{d}_{\mathrm{v}}\right)$ (Equation (2)), standard deviation (Equation (3)) and coefficient of variation (Equation (4)).

$$
\begin{gathered}
\bar{d}=\frac{\sum_{i=1}^{n} m_{i} d_{i}}{\sum_{i=1}^{n} m_{i}} \\
d_{v}=\frac{\sum_{i=1}^{n} d_{i}^{4}}{\sum_{i=1}^{n} d_{i}^{3}} \\
S D_{D}=\sqrt{\frac{1}{n-1} \sum_{i=1}^{n}\left(d_{i}-\bar{d}\right)^{2}} \\
C V_{D}=\left(\frac{S D_{D}}{\bar{d}}\right) \times 100
\end{gathered}
$$

Where $d_{i}=$ the diameter of the droplet in each set $(\mathrm{mm}), m_{i}=$ the droplet number, $i=$ the number of droplets in the set, $\bar{d}=$ the arithmetic mean droplet, $d_{v}=$ the volume weighted average droplet diameter, $S D_{D}=$ the standard deviation and $C V_{D}=$ the coefficient of variation.

\section{Results and Discussion}

\subsection{Gun sprinkler range}

Pressure, flow rate, nozzle type and diffuser are factors influenced the range of gun sprinkler. Table (2) shows the change in sprinkler range using different types of nozzle at three levels of operating pressure. The sprinkler range directly increased by the increase of operating pressure for types of nozzles, and it was $20.5,21.5$, and $24 \mathrm{~m}$ at 2,3 , and 4 bar respectively for circular nozzle. The gun sprinkler range was slightly reduced using both square and triangle nozzles comparing with circular nozzle. The lowest reduction was 2.33 and $2.38 \%$ for SN and TN at 3 bar perspectively and the highest reduction was 9.76 and $8.10 \%$ for $\mathrm{SN}$ and $\mathrm{TN}$ at 2 bar perspectively. The range reduction percentage was higher using diffuser for all nozzle types, and the lowest reduction was $18.75,26.19$, and $21.43 \%$ for CND, SND, and TND perspectively where the highest was $21.95,30.43$, and $28.95 \%$ for CND, SND, and TND perspectively. The higher reduction of sprinkler range as a result of using a diffuser 
vane was due to the diffuser vane produced a wider spray jet for the same operating pressure, and it reduced the kinetic energy of the water jet (Massey, 2005).

Table 2: The gun sprinkler range and its reduction percentage of different tested nozzles under three operating pressure.

\begin{tabular}{ccccc}
\hline Nozzle type & $\begin{array}{c}\text { Operating pressure, } \\
\text { bar }\end{array}$ & Flow rate, $\mathbf{~ m}^{\mathbf{3}} \mathbf{h r}$ & $\begin{array}{c}\text { Gun sprinkler } \\
\text { range, } \mathbf{~ m}\end{array}$ & $\begin{array}{c}\text { Range reduction, } \\
\mathbf{\%}\end{array}$ \\
\hline \multirow{3}{*}{ CN } & 2 & 1.271 & 20.5 & 0 \\
& 3 & 1.591 & 21.5 & 0 \\
& 4 & 1.825 & 24.0 & 0 \\
\hline \multirow{3}{*}{ SN } & 2 & 1.271 & 18.5 & 9.76 \\
& 3 & 1.591 & 21.0 & 2.33 \\
& 4 & 1.825 & 23.0 & 4.17 \\
\hline \multirow{3}{*}{ TN } & 2 & 1.224 & 19.0 & 8.10 \\
& 3 & 1.5 & 21.0 & 2.38 \\
& 4 & 1.78 & 22.5 & 6.52 \\
CND & 2 & 1.193 & 16.0 & 21.95 \\
& 3 & 1.461 & 17.0 & 20.93 \\
& 4 & 1.724 & 19.5 & 18.75 \\
\hline \multirow{3}{*}{ SND } & 2 & 1.244 & 15.0 & 29.73 \\
& 3 & 1.458 & 16.0 & 26.19 \\
& 4 & 1.659 & 17.0 & 30.43 \\
\hline \multirow{2}{*}{ TND } & 2 & 1.278 & 15.0 & 28.95 \\
& 3 & 1.539 & 17.0 & 21.43 \\
& 4 & 1.723 & 18.5 & 24.44 \\
\hline
\end{tabular}

\subsection{Precipitation distribution pattern}

The shape of the water precipitation distribution pattern is mainly determined by the sprinkler model and its internal design, discharge angle, the number and type of nozzles and the working pressure. One of the other factors affecting the water distribution pattern is the use of a jet straightening vane (Tarjuelo et al., 1999). Fig. (6) Shows the precipitation pattern of three nozzle types with and without diffusion vane. A doughnut-shaped distribution patterns were noticed for $\mathrm{CN}$ nozzle at the three levels of operating pressure, which wast water and reduce sprinkler irrigation quality. The precipitation was 72,74 , and $77 \mathrm{~mm} / \mathrm{hr}$ at distances 15,17 , and $18.54 \mathrm{~m}$ from sprinkler under 2, 3, and 4 bar operating pressure respectively, then it deceased to 26,29 , and $16 \mathrm{~mm} / \mathrm{hr}$ at distances $18.5,20$, and $21.5 \mathrm{~m}$ under 2,3 , and 4 bar operating pressure respectively. The use of both SN and TN nozzles improved the water precipitation pattern. The precipitation rate of SN was 78,80 , and $82 \mathrm{~mm} / \mathrm{hr}$ at a distances $11,12.5$, and $12.5 \mathrm{~m}$ from gun sprinkler, then it decreased gradually to 12,18 , and 23 at distances $18.5,20$, and 21.5 m under 2, 3, and 4 bar operating pressure respectively. It can be seen that the precipitation pattern at 3 and 4 bar produced a triangular shape and it was better than the precipitation pattern at 2 bar operating pressure. The precipitation pattern curve of $\mathrm{TN}$ was rectangular shaped comparing the curve of $\mathrm{SN}$ at the different levels of operating pressure. It was 73,78 and $100 \mathrm{~mm} / \mathrm{hr}$ at distances 11,12 , and $13 \mathrm{~m}$ from gun sprinkler under 2,3 , and 4 bar operating pressure respectively then the precipitation rate decreased to 28,15 , and $18 \mathrm{~mm} / \mathrm{hr}$ at 17,20 , and $20 \mathrm{~m}$. Generally, the non-circular shape nozzles improved the water precipitation pattern comparing the circular one that agreed with (Abd El-Mageed et al., 2009, and Li et al., 1994). 


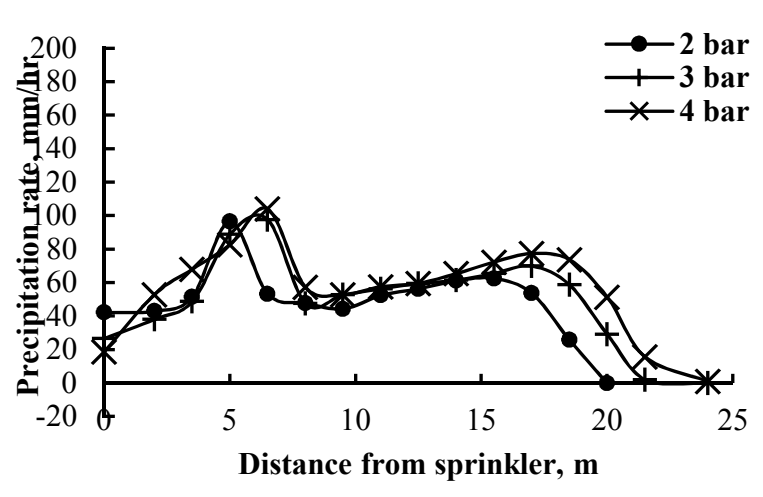

$\mathrm{CN}$

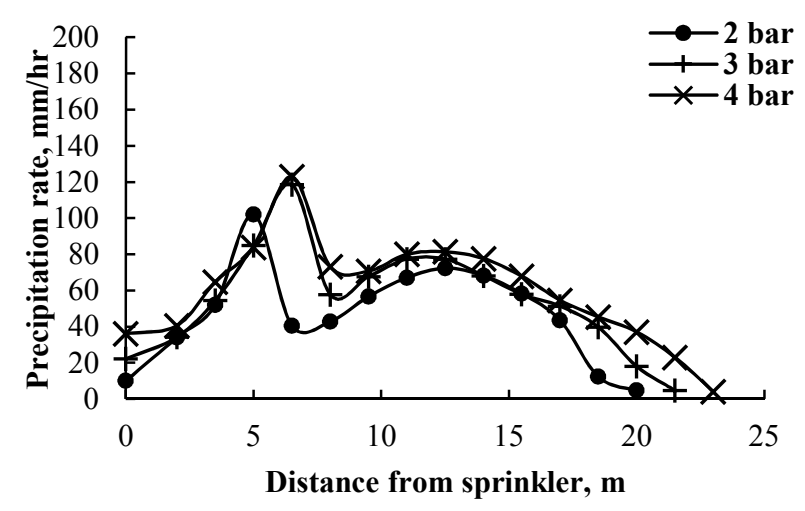

SN

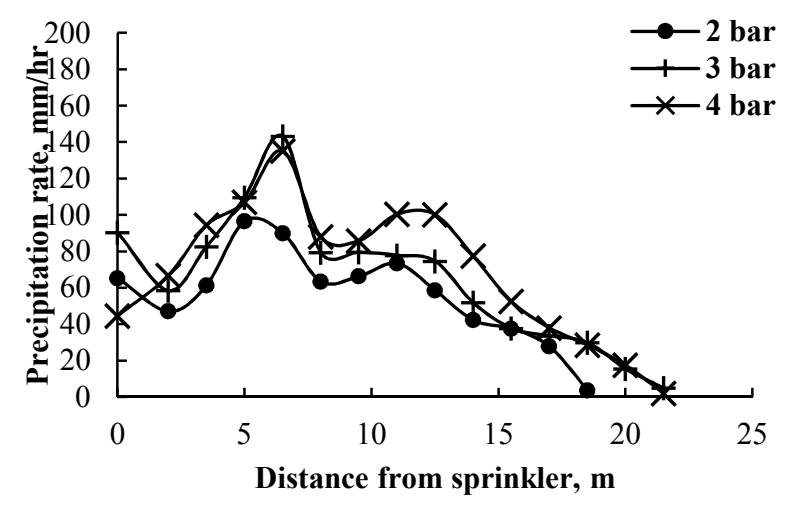

TN

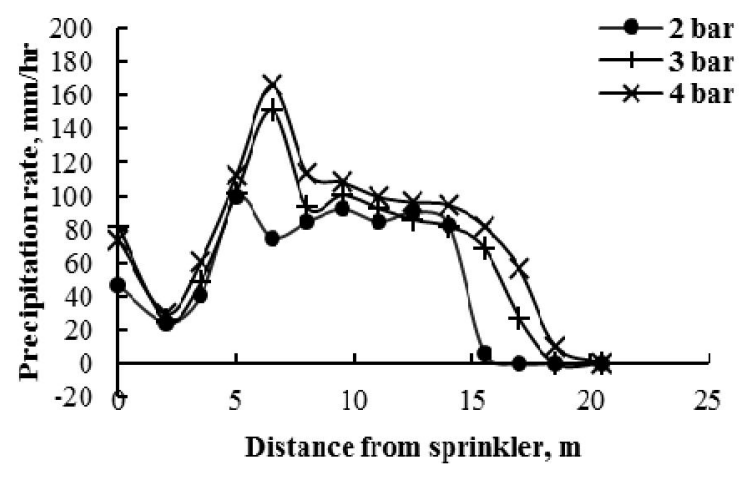

CND

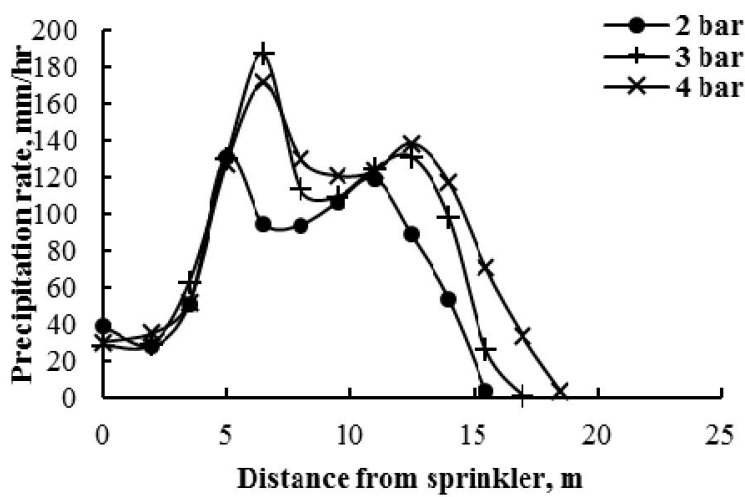

SND

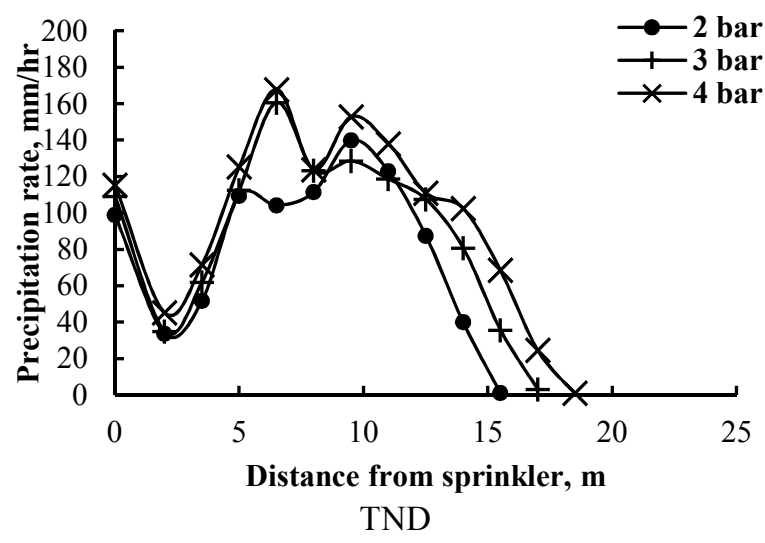

Fig. 6: Water distribution profiles for the three types of nozzles.

The improvement of precipitation pattern using non-circular nozzles was due to that every vertex of the square or triangle nozzle works as a spray emission point that throw the water jet at a different radius along the sprinkler range. So, the SN nozzle have four emission points and produced a better precipitation pattern than TN nozzle which have three emission point as it can be seen in (Fig. 7), where $\mathrm{CN}$ nozzle produced only one emission point with only one spray range.

The three types of nozzles using the diffuser vane CND, SND, and TND produced the doughnutshaped precipitation patterns as it be seen in (Fig. 7). The precipitation rates of CND were 92, 100, and $108 \mathrm{~mm} / \mathrm{hr}$ at $9.5,10$, and $11 \mathrm{~m}$ then it reduced to 20,27 , and 25 at 15,17 , and $18 \mathrm{~m}$ under 2,3 , and 4 bar operating pressure respectively. The SND nozzle precipitation rates were 119,131 , and $139 \mathrm{~mm} / \mathrm{hr}$ at $11,12.5$, and $13 \mathrm{~m}$ then it reduced to 20,26 , and $33 \mathrm{~mm} / \mathrm{hr}$ at 15,17 , and $17.5 \mathrm{~m}$ under 2,3 , and 4 bar operating pressure respectively. TND nozzle produced precipitation rates of 140, 129, and 153 $\mathrm{mm} / \mathrm{hr}$ at $9,9.5$ and $10 \mathrm{~m}$ then it reduced to 20,36 , and $25 \mathrm{~mm} / \mathrm{hr}$ at 14.515 .5 , and $17 \mathrm{~m}$ under 2,3 , and 4 bar operating pressure respectively. it can be noticed from the results that, the use of diffuser vane of $15^{\circ}$ diffusion angle was not suitable for low operating pressure (2,3, and 4 bar). 


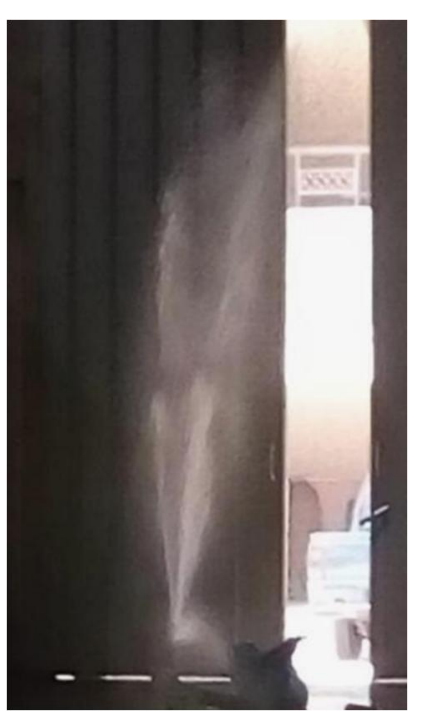

(a)

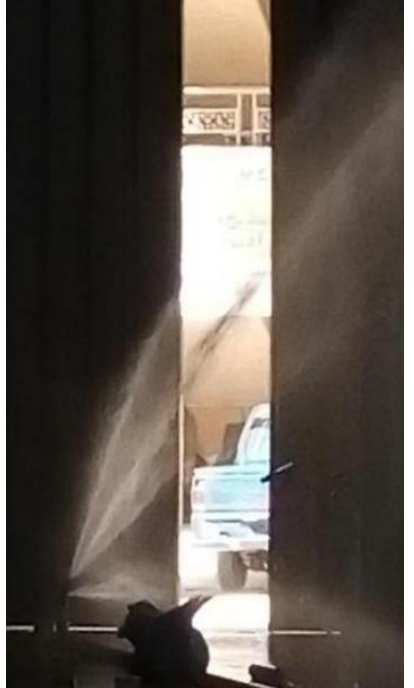

(b)

Fig. 7: Water jet of non-circular nozzles: a. square nozzle (SN), and b. triangle nozzle (TN).

\subsection{Droplet size distribution}

Results of droplet size were obtained at the edge of wetted radius. The weighted cumulative frequency means the cumulative ratio between the weighted of droplets under specific size and the total weighted of the spray. Fig. (8) Show the relationship between the weighted cumulative frequency percentage and the droplet diameter at 2, 3, 4 bar operating pressure. It can be noted that the weighted cumulative frequency increased along the gun sprinkler range for $\mathrm{CN}$ nozzle and the largest droplet diameter was at the spray far terminal and it was decreased by the increase of operating pressure. The mean droplet diameters were between $0-8.6,0-6$, and $0-4.25 \mathrm{~mm}$, and the weighted cumulative frequency under $3 \mathrm{~mm}$ droplet diameter was 28,34 , and $31 \%$, under $4 \mathrm{~mm}$ it was 51,77 , and $86 \%$, under $5 \mathrm{~mm}$ it was $63,87.5$, and $100 \%$ at 2, 3, 4 bar operating pressure respectively. The droplet diameters were larger for CND nozzle comparing CN nozzle. The mean droplet diameters of CND nozzle were between $0-4,0-6.5$, and $0-6.5$ at 2, 3, 4 bar operating pressure respectively. The weighted cumulative frequency under $3 \mathrm{~mm}$ droplet diameter was 32,25 , and $38 \%$, under $4 \mathrm{~mm}$ it was 54,56 , and 83 , under $5 \mathrm{~mm}$ it was 74,79 , and $92 \%$ at 2, 3, 4 bar operating pressure respectively. The distribution of droplet diameters of $\mathrm{SN}$ nozzle were higher compared with $\mathrm{CN}$. The mean droplet diameters of SN nozzle were between $0-7,0-6.5$, and $0-6.5 \mathrm{~mm}$ and the weighted cumulative frequency under $3 \mathrm{~mm}$ droplet diameter was 15,11 , and 15 , under $4 \mathrm{~mm} 60,43$, and 50 , under $5 \mathrm{~mm}$ 71,77 , and 72 at 2, 3, 4 bar operating pressure respectively. The use of SND decreased the droplet size specially under 3, and 4 bar operating pressure compared with $\mathrm{CN}$, and SN nozzles.pared with CN.

The mean droplet diameters of SND were between $0-6.5,0-4.7$, and $0-5$. The distribution of

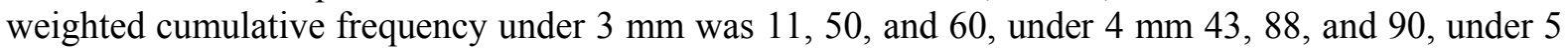

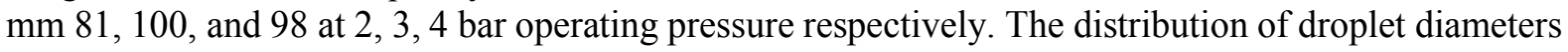
using TN nozzle were higher compared with $\mathrm{CN}$ and SN nozzles. The mean droplet diameters of NT were between $0-8.7,0-7$, and $0-8.3 \mathrm{~mm}$, and the weighted cumulative frequency under $3 \mathrm{~mm}$ was 18,11 , and 17 , under $4 \mathrm{~mm}$ was 41,42 , and 65 , under $5 \mathrm{~mm}$ was 56,65 , and 80 . The use of TND nozzle decreased the droplet diameters and gave results near to that of SND. The mean droplet diameters of NTD were between $0-8.7,0-5.5$, and $0-4.7 \mathrm{~mm}$ and the weighted cumulative frequency under $3 \mathrm{~mm}$ was 23,48 , and 65 , under $4 \mathrm{~mm}$ was 43,78 , and 90 , under $5 \mathrm{~mm}$ was 60,95 , and 100 at 2, 3, 4 bar operating pressure respectively. 


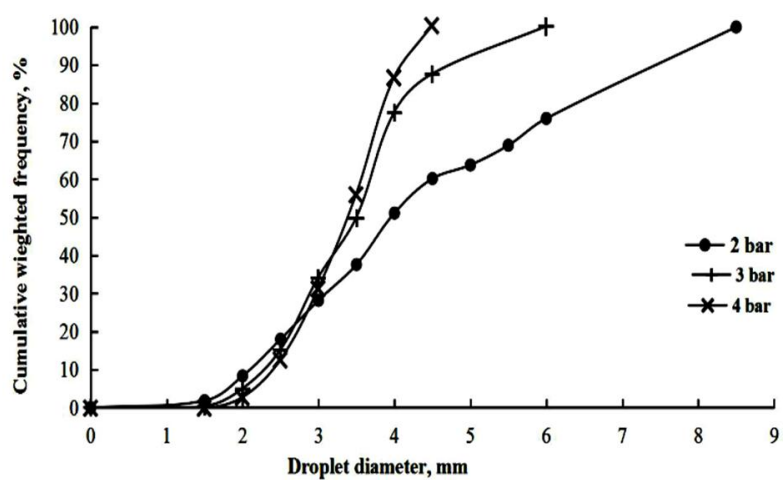

$\mathrm{CN}$

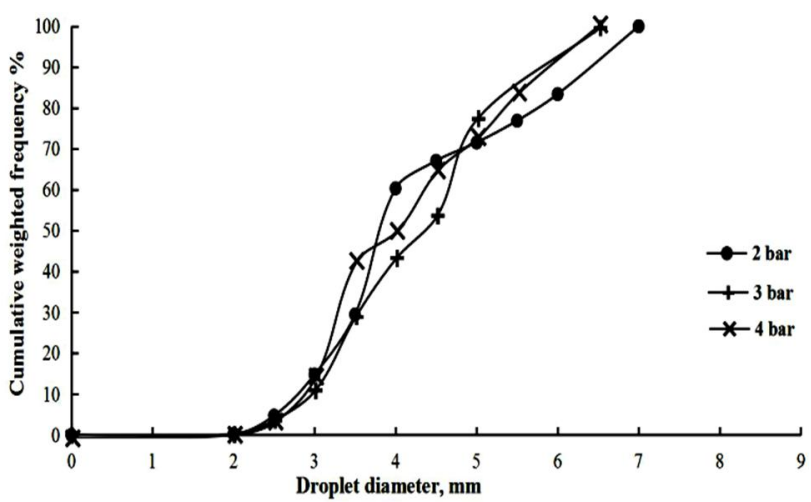

$\mathrm{SN}$

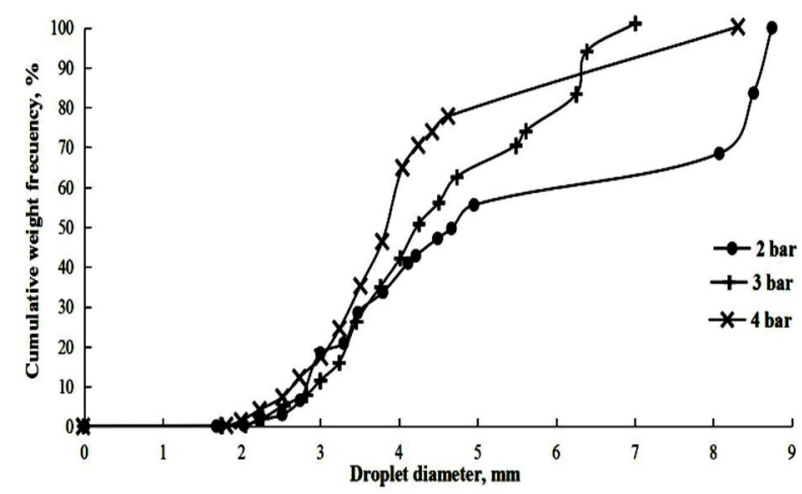

TN

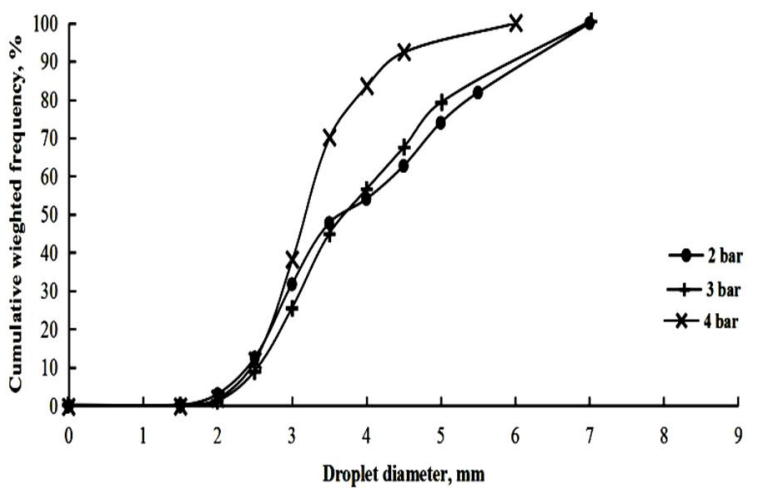

CND

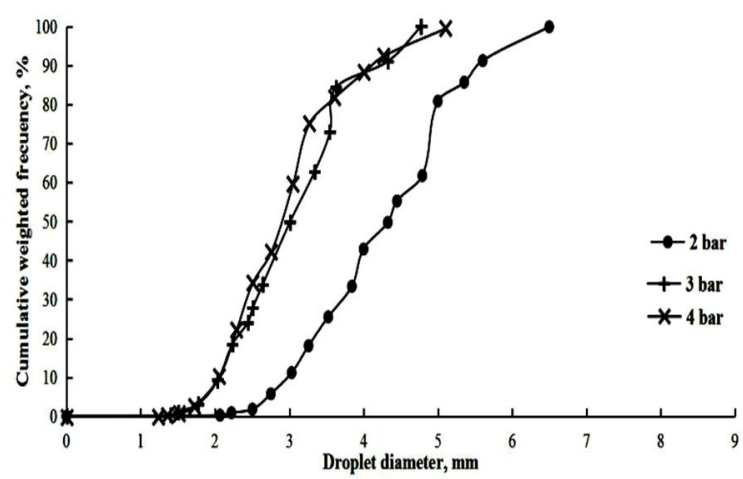

SND

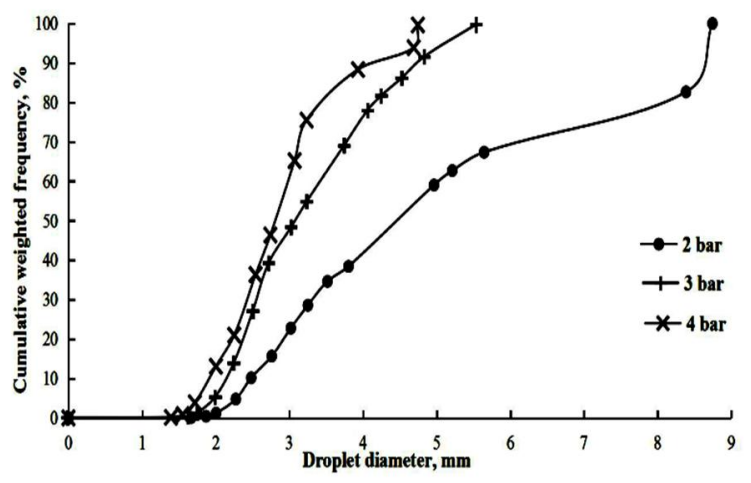

TND

Fig. 8: Droplet size distributions for the three types of nozzles.

\section{Statistical analysis of droplet diameter}

Table (3) presents the statistical parameters of droplet size diameter at three operating pressure. Theses parameters are the arithmetic mean, standard deviation, coefficient of variation, and the volumetric mean diameter. There was a general decrease in mean droplet diameters of theses parameters by the increase of operating pressure.

The standard deviation of the droplet diameter for SND nozzle was ranged from $0.66 \mathrm{~mm}$ to 0.96 $\mathrm{mm}$ with a mean value of $0.81 \mathrm{~mm}$, which recorded the lowest coefficients in diameter variation ranged from 27.30 to $27.95 \%$ with a mean value $27.63 \%$. For CN nozzle, the standard deviation of the droplet diameter was rangeed from $0.67 \mathrm{~mm}$ to $0.85 \mathrm{~mm}$ with a mean value $0.76 \mathrm{~mm}$, the coefficients in diameter variation ranged from 23.63 to $47.84 \%$ with a mean value $35.74 \%$. 
Table 3: Statistical parameters of droplet diameters for different types of nozzles under three operating pressures.

\begin{tabular}{|c|c|c|c|c|c|c|c|c|c|c|c|c|}
\hline $\begin{array}{c}\text { Nozzle } \\
\text { type }\end{array}$ & & $\overline{\boldsymbol{d}}, \mathbf{m m}$ & & & $d_{v}, \mathbf{m m}$ & & & $D_{D}, \mathbf{m}$ & & & $C V_{D}, \%$ & \\
\hline $\begin{array}{c}\text { Operating } \\
\text { pressure, } \\
\text { bar }\end{array}$ & 2 & 3 & 4 & 2 & 3 & 4 & 2 & 3 & 4 & 2 & 3 & 4 \\
\hline $\mathrm{CN}$ & 2.31 & 2.71 & 2.85 & 4.74 & 3.63 & 3.33 & 1.10 & 0.85 & 0.67 & 47.84 & 31.41 & 23.63 \\
\hline SN & 3.33 & 3.41 & 3.26 & 4.35 & 4.74 & 4.18 & 0.95 & 1.05 & 0.91 & 28.54 & 30.79 & 28.06 \\
\hline $\mathbf{T N}$ & 3.29 & 3.43 & 3.07 & 5.76 & 4.58 & 4.58 & 1.30 & 1.08 & 0.98 & 39.57 & 31.45 & 32.07 \\
\hline CND & 2.73 & 3.01 & 2.82 & 4.26 & 4.31 & 3.39 & 1.02 & 0.95 & 0.66 & 37.26 & 31.43 & 23.27 \\
\hline SND & 3.50 & 2.40 & 2.35 & 4.35 & 3.10 & 2.99 & 0.96 & 0.72 & 0.66 & 27.30 & 29.74 & 27.95 \\
\hline TND & 2.97 & 2.56 & 2.34 & 5.24 & 3.33 & 2.93 & 1.16 & 0.72 & 0.62 & 38.88 & 27.91 & 26.56 \\
\hline
\end{tabular}

\section{Conclusions}

The effect of three types of nozzle orifice geometric shapes (Circular, square, and triangle) and diffuser vane were investigated on the precipitation pattern and droplet size of gun sprinkler under 2, 3, and 4 bar operating pressures. The results showed that:

The use of non-circular shape nozzles reduced the gun sprinkler range within 2.33 to $9.76 \%$, but the use of diffuser vane reduced the range within 18.75 to $30.43 \%$.

The non-circular shape nozzles improved the water precipitation pattern comparing the circular one. It produced a precipitation pattern with triangle shape and rectangle shape for SN and TN nozzle respectively.

The CN nozzle produced droplet diameter less than $5 \mathrm{~mm}$ under 4 bar operating pressure while both $\mathrm{SN}$ and TN nozzles had no significant effect on droplet diameter under different operating pressures.

The use of diffuser vane reduced the droplet diameter near to $5 \mathrm{~mm}$ for SND and TND nozzles under 3 and 4 bar operating pressures.

The mean droplet diameter (arithmetic, and volumetric) decreased by increasing pressure, and SND gave the best droplet sizes.

It is recommendable to perform more investigations on the use of both the square nozzle orifice with the diffuser vane to improve the hydraulic performance and to produce a small droplet diameter under low operating pressure conditions.

\section{References}

Keller, J., and R.D. Bliesner, 1990. Sprinkle and Trickle Irrigation, Springer Science + Business Media New York, 49 - 51.

Massey, B., 20005. Mechanics of Fluids, $8^{\text {th }}$ ed., Taylor \& Francis Group, London and New York, : 244.

Abdel-mageed, H. M., A.M. El-Berry, M.H. Ramadan and M.A. El-Adl, 2009. Computer modeling for design and performance of on-demand low pressurized irrigation systems, $\mathrm{PhD}$ Thesis of Agricultural Engineering, Agric. Engineering Dept., Fac. of Agric., Al-Mansoura Univ., Egypt 134.

Mostafa, H. and A. Derbala, 2013, Performance of supplementary irrigation systems for corn silage in the sub-humid areas, Agric Eng Int: CIGR Journal Open access at http://www. cigrjournal. Org., $15(4): 9-15$.

Ismail, S.M., 2009. Design and Management of Field Irrigation Systems. Bostan Al-Marifa, Kafr ElDwar, Egypt: 129 - 171.

Lin, S.P., 2003, Breakup of liquid sheets and jets, Cambridge University Press The Edinburgh Building, Cambridge, United Kingdom, 1.

Kooij, S., R. Sijs, M. Morton, M.M. Denn, E. Villermaux, and D. Bonn, 2018, What Determines the Drop Size in Sprays? Published by the American Physical Society, 10.1103/ Phys Rev X.8.031019. 
Solomon, K.H., D.C. Kincaid and J.C. Bezdek, 1985. Drop size distributions for irrigation spray nozzles. Trans. of the ASAE, 28 (6):1966-1974.

Montero, J., J.M. Tarjuelo, and P. Carrion, 2003. Sprinkler droplet size distribution measured with an optical spectropluviometer, Irrig. Sci., 22: 47-56.

Li, J., 1997. Effect of Pressure and Nozzle Shape on the Characteristics of Sprinkler Droplet, J. Agric . Eng. Res., 66: $15-21$.

Li, J., H. Kawano, and K. Yu, 1994. Droplet size distributions from different shaped sprinkler nozzles. Transactions of The ASAE 37 (6): 1871-1878.

Tarjuelo, J.M., J. Montero, P.A. Carrion, F.T. Honrubia, and M.A. Calvo 1999. Irrigation uniformity with medium size sprinkler. I. Characterization of water distribution in no-wind conditions. Transactions of the ASAE, 42(3): 665-676. 